\title{
ESTRUCTURA Y FORMA DE LA CIUDAD A TRAVÉS DE LA CARTOGRAFÍA HISTÓRICA: CASTRO URDIALES, CANTABRIA $(1800-1960)^{1}$
}

\author{
Carmen Delgado Viñas \\ Departamento de Geografía, Urbanismo y Ordenación del Territorio \\ Universidad de Cantabria
}

\section{RESUMEN}

El presente artículo se plantea como objetivo el análisis de la evolución estructural y morfológica de un espacio urbano de rango y tamaño modestos, Castro Urdiales (Cantabria), desde su condición histórica de villa marinera hasta su consolidación como ciudad industrial moderna.

Desde una perspectiva metodológica, la parte más substancial del análisis de la dinámica urbanística se apoya esencialmente en el uso de las imágenes cartográficas, como referencias documentales que proporcionan datos y testimonios que no se encuentran en otras fuentes.

No obstante, como sucede con otras fuentes documentales, la información obtenida de mapas y planos ha sido combinada y complementada con otro tipo de fuentes coetáneas a las cartográficas. Y, por descontado, se han adoptado las oportunas precauciones, similares a las tomadas con las fuentes escritas, sobre posibles errores de información mediante el contraste y la comparación de unas y otras fuentes, cartográficas y literarias.

Palabras clave: Cartografía histórica, Geografía urbana, Dinámica urbanística, Cantabria, Castro Urdiales.

\section{ABSTRACT}

\section{Structure and morphology of town through the historical cartography:} Castro Urdiales, Cantabria (1800-1960)

This article aims at analyzing the structural and morphological dynamics of an urban space with a modest rank and size, Castro Urdiales (Cantabria), from its historic status as a fishing town to its consolidation into a modern industrial city.

From a methodological perspective, the most substantial part of the analysis of urban dynamics is essentially based on the use of cartographic images, like documentary references that provide data and testimonials which are not found in other sources.

However, as with other documentary sources, the information obtained from maps and plans had to be combined and complemented with other sources contemporaneous of those cartographic ones. And, of course, appropriate precautions have been adopted, similar to those taken with the written sources, contrasting information about possible errors and comparing with other sources, both cartographic and literary.

Keywords: Historical Cartography, Urban Geography, Urban dynamics, Cantabria, Castro Urdiales.

La temática de la dinámica espacial urbana ha sido abordada con relativa frecuencia por bastantes autores para un nutrido acervo de ciudades españolas, generalmente de dimensiones medias o grandes. Asimismo, en tales estudios se ha recurrido de forma sistemática al uso de cartografía histórica, general-

\footnotetext{
Contacto: carmen.delgado@unican.es
}

1 Este estudio se apoya en la investigación realizada en el marco del Proyecto "Los paisajes patrimoniales de la España atlántica y Navarra (CSO2012-39564-C07-05) del Plan Nacional de I+D+I del Ministerio de Economía y Competitividad. 
mente con la finalidad de ilustrar lo expuesto en los textos como resultado de la investigación realizada a partir de otras fuentes documentales.

En bastantes menos ocasiones se han utilizado los mapas y planos históricos como fuentes por sí mismos para cimentar la investigación en la información obtenida directamente a partir de estos documentos. Es esta última la modalidad metodológica que se ha aplicado en este estudio, el uso de las imágenes cartográficas como referencias documentales que proporcionan datos y testimonios, que no se encuentra en otras fuentes, sobre los que se apoya la parte más substancial del análisis de la dinámica urbanística.

No obstante, es preciso advertir que este método de trabajo impone una serie de restricciones y requerimientos que no siempre es posible satisfacer.

En primer lugar, es imprescindible disponer de un amplio repertorio de mapas que permitan establecer una secuencia temporal adecuadamente nutrida. En este sentido es necesario tener en cuenta que apenas se dispone de cartografía urbana anterior a la Edad Moderna, cuando las representaciones espaciales empezaron a ser utilizadas como herramientas de conocimiento y dominio del territorio y, en consecuencia, también de control del espacio urbano. Pero esta condición afecta en primer lugar, como es lógico, a las ciudades de mayor importancia, las que eran expresión del poder, mientras que el proceso es muy posterior en el caso de las villas y pequeñas ciudades. A ello hay que añadir que la cartografía española estaba aún muy retrasada durante el siglo XVIII y la primera mitad del siglo XIX (Canosa y García, 2008; Quirós, 2008). Esta situación explica que, en la mayor parte de los casos, sea obligado establecer el punto de partida cronológico de este tipo de estudios en la cartografía urbana militar de la primera mitad del siglo XIX, en particular en los planos levantados para las ciudades que fueron objeto de asedios por parte de los ejércitos franceses, que elaboraron una cartografía de gran calidad cuyo propósito era mejorar el conocimiento del territorio para facilitar su dominio.

Los mapas utilizados como fuentes de información, por otro lado, deberían permitir averiguar las circunstancias en que fueron elaborados. En este aspecto conviene recordar que los mapas no son el territorio mismo sino imágenes que representan, a través de símbolos visuales codificados, algunos aspectos seleccionados de un territorio. El mapa es, en consecuencia, una construcción sociocultural que nos permite adquirir un conocimiento aproximado del territorio mediante la decodificación e interpretación del sistema de signos utilizados. Con tal propósito es deseable conocer la fuente de procedencia del mapa, su autoría y la intencionalidad de su elaboración para entender correctamente la elección de los elementos significativos representados así como las omisiones, involuntarias o deliberadas.

A ello hay que añadir que, como sucede con otras fuentes documentales, la información que proporcionan mapas y planos tiene que ser obligatoriamente combinada y complementada con otro tipo de fuentes coetáneas a las cartográficas, al modo en que el profesor Quirós ha utilizado, con gran maestría, el Diccionario de Madoz y el Atlas de Coello en su obra sobre las ciudades españolas del siglo XIX (Quirós, 1991 y 2009). Y, por descontado, adoptar las oportunas precauciones, similares a las tomadas con las fuentes escritas, sobre posibles errores de información mediante el contraste y la comparación de unas y otras fuentes, cartográficas y literarias.

\section{CASTRO URDIALES EN SU CONTEXTO TERRITORIAL Y SOCIOECONÓMICO}

El término municipal de Castro Urdiales es uno de los más extensos de Cantabria $\left(96,7 \mathrm{~km}^{2}\right)$ y también de los más poblados, con 32.309 habitantes empadronados en 2013, la mayor parte de los cuales, 25.514, reside en la capital municipal, la ciudad homónima de Castro Urdiales. Está ubicado en la linde oriental de la región, en "la raya de Vizcaya y las Encartaciones", una situación limítrofe que ha sido, y es, la principal clave para entender la dinámica espacial del espacio urbano de Castro Urdiales desde hace casi dos milenios hasta la actualidad (Delgado, 2011b).

Las primeras referencias a la ocupación humana y el aprovechamiento del actual territorio de Castro Urdiales corresponden al poblado autrigón de la Peña de Sámano, considerado como precursor lejano de la colonia romana de Portus Amanum, que fue elevada a la categoría de civitas en el año 74 d.C. por el emperador Tito Flavio Vespasiano con el nombre de Flavióbriga.

La actividad comercial y el propio núcleo de población sufrieron después una profunda crisis que se prolongó desde el siglo III d.C. hasta principios del siglo XII, cuando vuelve a aparecer citado un núcleo de población denominado, ahora, Castrum Ordiales. Alfonso VIII le otorgó en 1163 el Privilegio de Villazgo, según el modelo del Fuero de Logroño, con la finalidad de favorecer el poblamiento y facilitar la 
Figura 1. Itinerario de Valmaseda a Castro Urdiales (1870)

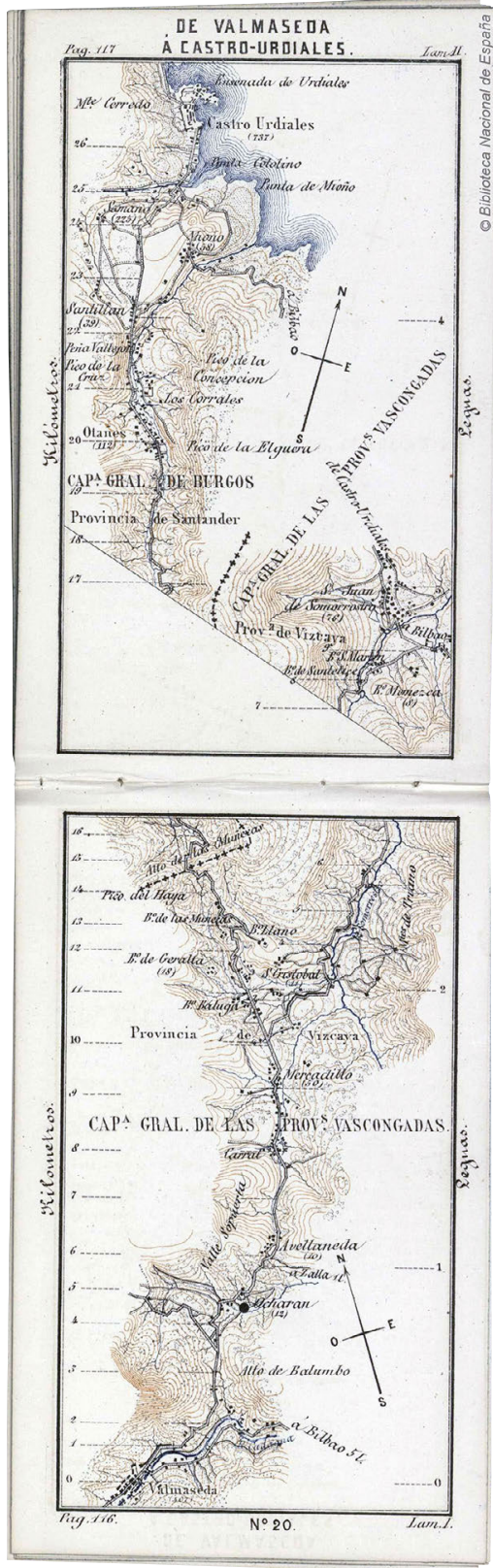

Fuente: Itinerario General Militar de España. Itinerario $n^{\circ}$ 20. Cuerpo de E.M. del Ejército. Capitanía General de las Provincias Vascongadas. Depósito de la Guerra, Año de 1870. Biblioteca Nacional de España. organización político-administrativa del territorio, convirtiéndolo así en la primera población aforada cántabra y la principal villa marítima castellana.

A partir de ese momento la villa de Castro Urdiales asumió la función territorial de una "ciudad de frontera" en un doble sentido: frontera litoral septentrional del Reino de Castilla y frontera de éste con el Señorío de Vizcaya al que estuvo unida, con voz y voto, desde 1394 hasta 1471.

Desde la Edad Media, el núcleo de Castrum Ordiales fue, ante todo, una "villa marinera" especializada en la pesca y en las actividades relacionadas con ella. Entre otras, la producción conservera basada en técnicas tradicionales que tenían una larga tradición en la villa castreña, en particular la del escabechado. De ello existen algunos testimonios que documentan el comercio de pescado, tanto fresco como elaborado, llevado por carreteros y mulateros desde Castro Urdiales hacia las áreas castellanas interiores (Fig. 1). A partir de estas actividades tradicionales, según apuntan todos los indicios, nació en Castro Urdiales la moderna industria conservera cántabra, a finales de la primera mitad del siglo XIX, que implicó la paulatina sustitución de la técnica del escabechado por la de salazón en salmuera desde mediados del siglo XIX ${ }^{2}$.

La primacía ostentada por Castro Urdiales en la producción conservera fue perdiendo terreno desde comienzos del siglo XX a medida que disminuían las capturas costeras de pescado. La causa fundamental del declive de la pesca debe atribuirse a los efectos de la contaminación de las aguas litorales a consecuencia de los vertidos de deshechos tras el auge que alcanzó la producción minera y la exportación de mineral de hierro a finales del siglo XIX. Fue precisamente esta actividad la que impulsó el desarrollo económico de Castro Urdiales desde que se reinició la explotación de algunas minas de hierro y la apertura de otras nuevas dispersas por el extremo nororiental del municipio, en el límite con Vizcaya.

El apogeo de la minería del hierro, entre 1880 y 1930, significó la consolidación de un fuerte núcleo de empresarios y comerciantes que actuaban en el área comprendida entre la villa castreña y la bilbaína, lo que, en consecuencia, supuso la intensificación de los vínculos anudados secularmente con Vizcaya. A este respecto, resulta sumamente significativo un mapa fechado en 1874, aunque posiblemente completado bastante más tarde, (Fig. 2) que representa el ámbito territorial comprendido entre los dos nodos económicos que centraban la cuenca minera, Castro Urdiales y Bilbao; en él están representados los principales elementos articuladores del territorio, los ferrocarriles construidos y en proceso de construcción que enlazaban los cotos con el puerto castreño y los cargaderos de mineral situados en varios puntos de la costa.

2 "Una porción numerosa de los naturales del país se dedica a la pesca: hay gremio de navegantes y pescadores, compuesto de cerca de 500 individuos que tripulan 80 lanchas sin cubierta... La pesca es por consiguiente la industria principal y más lucrativa y el comercio más seguro de estos moradores. Suben a muchos miles los quintales de varios pescados, entre ellos de bonito que es el más abundante, de merluza, de besugo, sardina y chicharro, que se cogen cada año; y se exportan a lomo por las recuas de los maragatos y arrieros que lo conducen á Madrid y otros muchos lugares de Castilla, en particular a Burgos, Aranda, Rioja, etc., a lo cual contribuye la carretera de Castro y Balmaseda hasta aquella ciudad....en los días en que se ha pescado, se llenan después del anochecer las fábricas de mujeres, que se ocupan hasta el alba en las labores y faenas de la limpia, escamadura, salazón y escabeche". Semanario Pintoresco Español, 1850, $n^{\circ} 31$, pp. 235-237. Trato estos aspectos con mayor extensión y profundidad en mi artículo publicado en revista Ería en 2011. 
Figura 2. Ámbito territorial de la cuenca minera comprendida entre Bilbao y Castro Urdiales

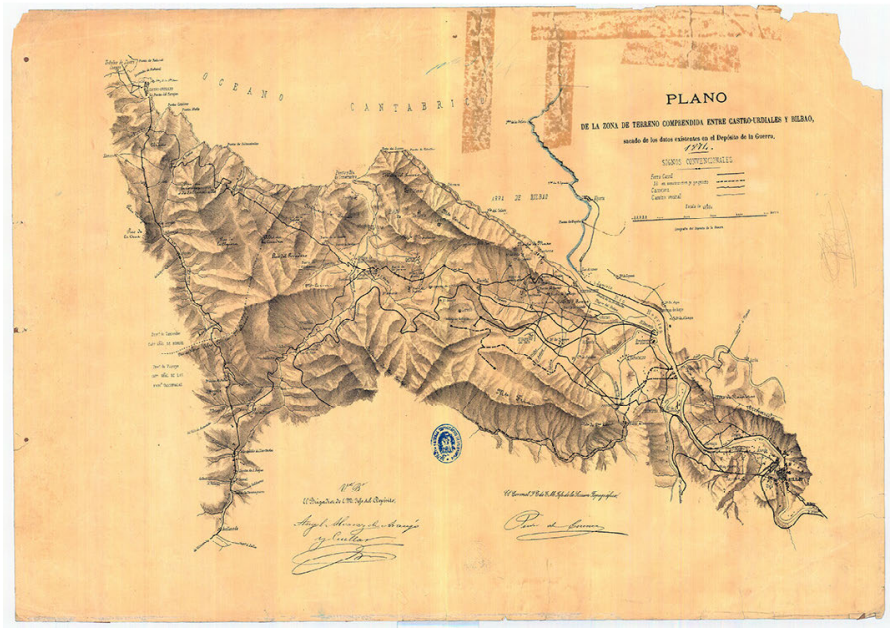

Fuente: Plano de la zona de terreno comprendida entre Castro Urdiales y Bilbao a tenor de los datos existentes en el Depósito de la Guerra, Pedro de Cuenca. Año 1874. CGE Ar.F-T.1-C.3-91

El puerto de Castro Urdiales había sido objeto de un primer proyecto de modernización presentado por el ingeniero militar José $\mathrm{M}^{\mathrm{a}}$ Mathé, nombrado director del mismo en 1831 (Ojeda, 2004). Su influencia en la posterior transformación urbanística de la ciudad fue muy grande aunque el proyecto no se llevó a cabo y, con la excepción de algunas obras realizadas en la Calle de la Mar a comienzos de la década de 1860 , las instalaciones portuarias apenas experimentaron mejora alguna durante décadas 3 .

Desde entonces, fueron creciendo las presiones de las empresas y colectivos interesados en la actividad portuaria y se presentaron numerosos proyectos.

En 1885 el Ayuntamiento de Castro Urdiales recibió un nuevo proyecto promovido, esta vez, por el empresario minero Luis Ocharan Mazas4. Este proyecto, tras experimentar algunas modificaciones, fue aprobado en noviembre de 1889 e inició definitivamente la mejora y modernización del puerto castreño (Fig. 3).

Figura 3. Proyecto de modernización del puerto de Castro Urdiales presentado por Luis Ocharan Mazas (Rafael Martín-Alberto Corral, 1884-1889)

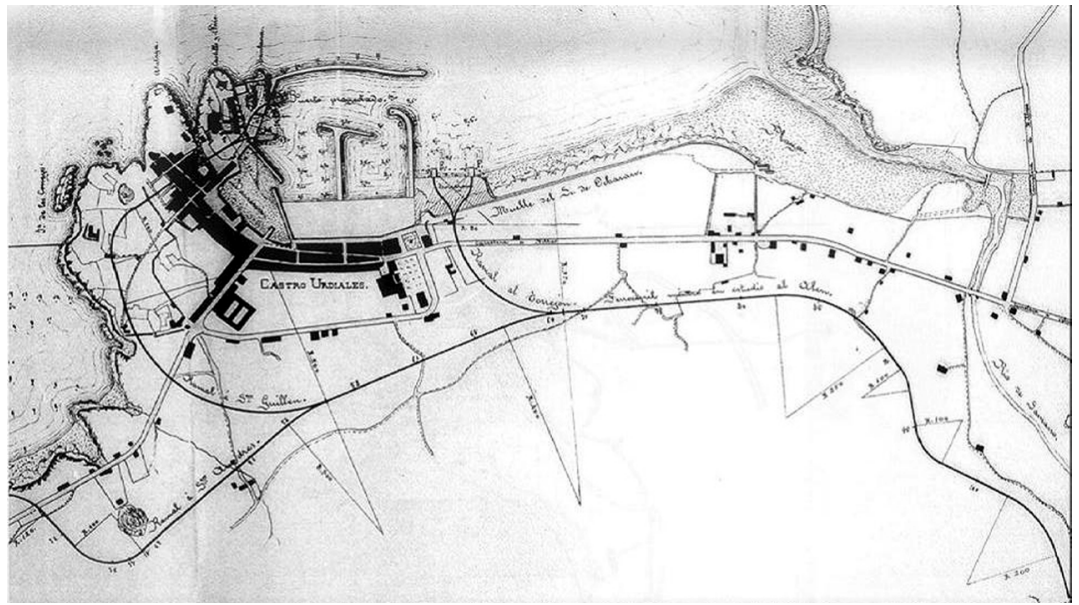

Fuente: Archivo General de la Administración. O.P., 1221, nº 52 (fragmento).

3 "se han hecho asimismo algunas diligencias para construir un muelle espacioso, en cuya obra ha trabajado un entendido ingeniero; pero creo que todo esto, como el muelle de Laredo, .... como tantos otros proyectos de especie análogas, quedarán por ahora en ciernes sin llegar a su complemento." Semanario Pintoresco Español, 1850, n 31, pp. 235-237

4 "Real Orden de 30 de junio de 1886, autorizando, de conformidad con lo informado por la Sección Cuarta de la Junta Consultiva de Caminos, Canales y Puertos, a don Luis Ocharan Mazas, para que (...) construya en el puerto de Castro Urdiales, desde el jardín de la Barrera hasta el camino de la bajada a la playa un dique malecón..." 
El proyecto de Luis Ocharan era mucho más ambicioso puesto que, además de la edificación de un muelle sobre terrenos ganados al mar por relleno, preveía la construcción de ocho embarcaderos de mineral: cuatro de ellos en la ensenada de Urdiales, dos en las inmediaciones de San Guillén y otros dos en la punta del Torrejón. En el plano del proyecto figura, asimismo, el trazado de las vías férreas y los ramales que deberían llevar los minerales hasta los cargaderos para su embarque, de forma que el casco urbano, tanto el espacio edificado como el todavía sin urbanizar contiguo a aquél, quedaría rigurosamente ceñido y constreñido por el dogal formado por la retícula ferroviaria. La modernización del puerto quedó así directamente vinculada al proceso de expansión y urbanización que, por otro lado, estuvo estrictamente condicionado por el trazado de la red ferroviaria al servicio del puerto, que adquirió un gran protagonismo en el tejido urbano naciente ya que estuvo en funcionamiento hasta bien avanzado el siglo XX (Fig. 4).

Figura 4. El Puerto de Castro Urdiales en 1904

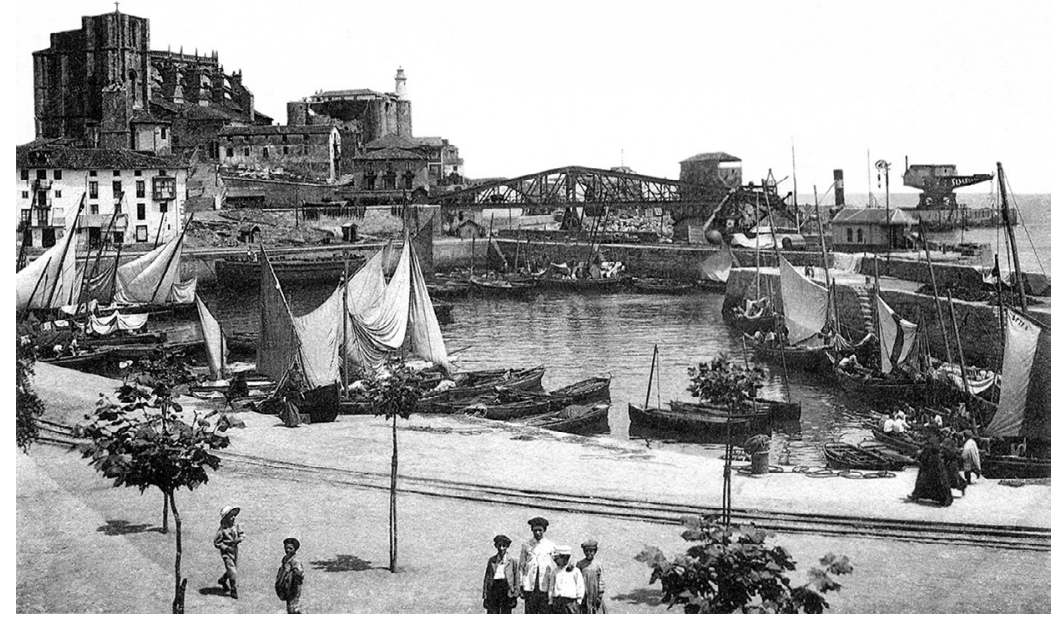

Fuente: Centro de Documentación de la Imagen de Santander

En febrero de 1892 se fundó la Compañía del Ferrocarril Minero Castro-Alén, promovida también por Luis Ocharan y domiciliada en la propia villa castreña. El trazado del ferrocarril, que permaneció activo hasta 1936, tuvo un extraordinario impacto en la morfología urbana ya que, además de constituir un nuevo límite para la ampliación de la ciudad en contigüidad con el casco histórico, entraba literalmente en el corazón de éste.

Dos años más tarde, en 1894, se constituyó la Compañía del ferrocarril de San Julián de Musques y Traslaviña (Arcentales, Vizcaya) a Castro Urdiales. Se trataba de un ferrocarril mixto, de mercancías y viajeros, que proponía mejorar las comunicaciones entre Castro Urdiales y Bilbao, en cuya estación de La Concordia finalizaba el recorrido del tren. Este ferrocarril estuvo en funcionamiento varias décadas, desde 1898 hasta su cierre definitivo en enero de 1966.

A través de la transformación de las infraestructuras de transporte, el puerto y los ferrocarriles, la minería modificó de manera radical la base económica de la villa, provocó el crecimiento de su población, modificó la organización social y alteró completamente la estructura y la forma del espacio urbano, impulsando su ampliación y modernización (Delgado, 2011a).

El auge del ciclo minero tuvo lugar en los años comprendidos entre finales del siglo XIX y comienzos del XX; el segundo lustro de esta centuria fue testigo del estancamiento y declive de la actividad extractiva y exportadora. El retroceso industrial fue coetáneo a la consolidación paulatina de las actividades vinculadas a lo que hoy llamaríamos el turismo residencial ${ }^{5}$, el veraneo de la burguesía madrileña y vasca,

5 A los frecuentes bailes que se celebran al aire "asisten las bellas y elegantes de la villa, y también las muchas personas que por la temporada de baños permanecen allí para tomar los de mar, a cuyo objeto van de provincias distantes y aun de la corte; de manera que a veces en los meses de julio y agosto trabajo cuesta hallar habitaciones y posadas en que alojarse." Semanario Pintoresco Español, 1850, n 31, pp. 235-237. "Tres edades humanas están allí representadas en el cantil de la costa, dentro de una distancia de media legua: Urdiales, la aldea primera, agrícola y pescadora ... Castro, la villa, la sociedad armada por necesidad para defender lo adquirido,... y en fin, la playa, la empresa de ayer, la industria nueva, que por encanto establece, mejora, modifica y crea ... Está la playa de baños en una entrada que hace la costa al saliente de la villa ... Salvo el número, el rostro, el habla y el vestido, las bañistas en Castro eran las que el viajero encuentra en el Lido de Venecia, y en el Biarritz de Gascuña, en la Caleta gaditana y en el Sardinero santanderino, en Brighton y en Ostende.". Amós de Escalante, Costas y Montañas: diario de un caminante, 1871. 
en particular la bilbaína, que seguía estando relacionada con las actividades de extracción y transporte de minerales.

La evolución económica brevemente reseñada explica la dinámica demográfica que experimentó Castro Urdiales a lo largo de los últimos siglos. La población de la villa, bastante mermada a principios del siglo XIX, experimentó un importante aumento como consecuencia del crecimiento económico vinculado al desarrollo de las actividades pesqueras y conserveras, primero, $y$, sobre todo, de la actividad minero-industrial desde las últimas décadas de la centuria. A partir de ese momento el ritmo de incremento poblacional fue espectacular: los 7.623 habitantes de 1877 se convirtieron en 9.466 en 1887 y en 14.191 en 1900.

Es obligado relacionar el declive de la industria conservera y la minería, no compensado por la importancia que empezaron a adquirir las actividades relacionadas con el ocio y esparcimiento estival, con el retroceso poblacional que tuvo lugar a partir de la segunda década del siglo XX, que abre una nueva etapa de decrecimiento y estancamiento demográfico. Desde 1910 el volumen de población se mantuvo en torno a 12.000 habitantes, cifra que la población municipal no superó hasta 1970.

\section{LA TRANSFORMACIÓN ESTRUCTURAL Y MORFOLÓGICA DEL ESPACIO URBANO CASTREÑO}

Según fuentes documentales escritas, el núcleo originario de la villa corresponde al sector conocido como el castro, emplazado en la parte más elevada de la pequeña península formada por dos promontorios localizados entre las ensenadas de Brazomar, al sureste, y de Urdiales, al noroeste, en la que se localizaba la diminuta aldea de la misma denominación; ambos lugares dieron conjuntamente nombre a la primitiva villa medieval, Castrum Ordiales, formada por un espacio mucho más amplio que el área edificada y cercado por una muralla que se completó a principios del siglo XIII (Fig. 5).

Figura 5. La villa de Castro Urdiales y sus inmediaciones en 1847

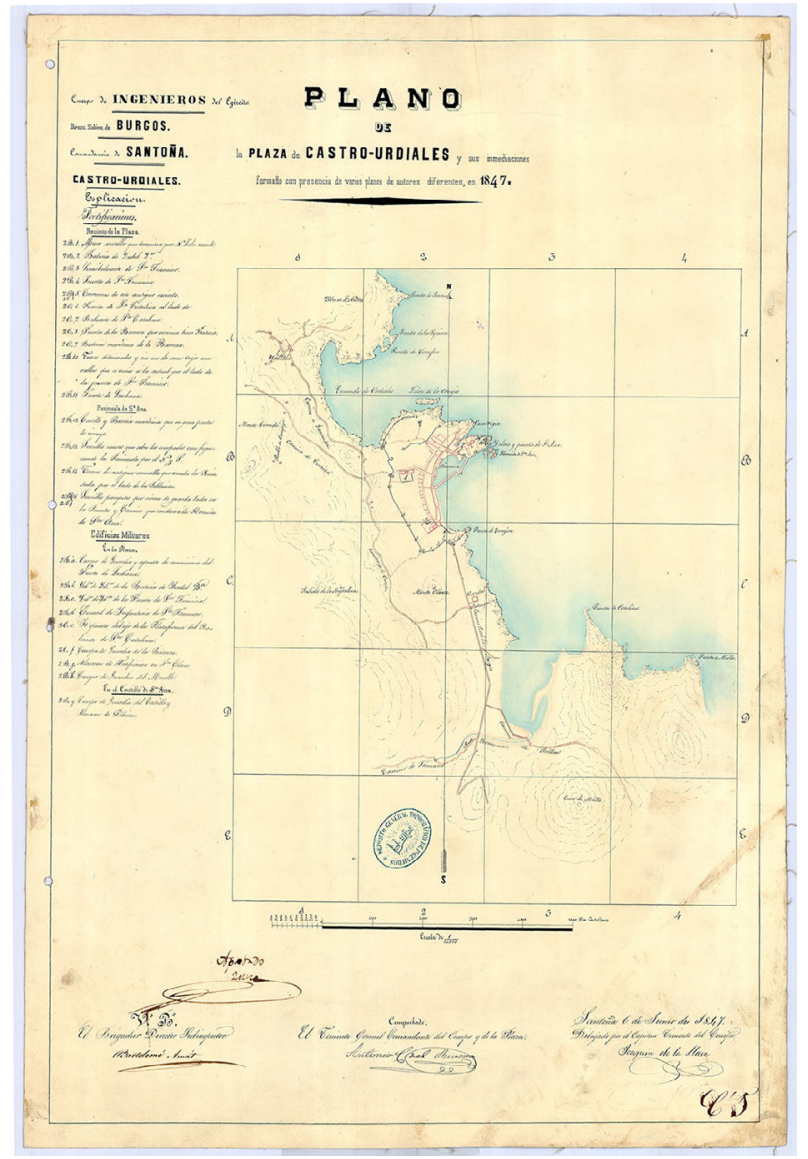

Fuente: Plano de la villa de Castro Urdiales y sus inmediaciones. Moreno y Lara. Año 1847. AGM, 17-b-7-53. (15.152). 
El castro, rodeado por su propia cerca, desempeñaba la función de ciudadela fortificada y en su interior se situaba la calle y la ermita románica de San Pedro, la iglesia gótica de Santa María de la Asunción, el hospital del mismo título, el cementerio y una fortaleza.

Adosada al castro se extendió en la Alta Edad Media la puebla vieja, conocida después como la media villa de arriba; era el núcleo residencial principal donde se localizaban las casas-torre de algunos de los linajes más poderosos. Estaba formada por un reducido número de calles articuladas por la Rúa Mayor y la plaza situada junto a la dársena vieja, centro neurálgico de la villa, donde se disponían los principales edificios públicos, como la Casa del Concejo y las Carnicerías.

La media villa de abajo era el sector de expansión bajomedieval organizado a partir de la Calle de Ardigales, prolongación de la Rúa Mayor, y la Calle de la Mar, que bordeaba el arenal, que antes separaba ambas pueblas, reconvertido en La Plazuela a partir del siglo XVI. En este sector urbano se levantaban los conventos de San Francisco y de Santa Clara, fundados a finales del siglo XIII.

Todo el conjunto amurallado se adaptaba perfectamente a la línea de base marcada por la dársena vieja y el puerto, que definieron la forma semicircular del plano durante varios siglos.

\subsection{La evolución urbanística durante el siglo XIX}

La forma de la villa castreña experimentó muy pocas variaciones hasta el siglo XIX, como muestra el mapa elaborado por el ejército francés y fechado en 1813 (Fig. 6).

Figura 6. Mapa de Castro Urdiales y su entorno durante el sitio de 1813
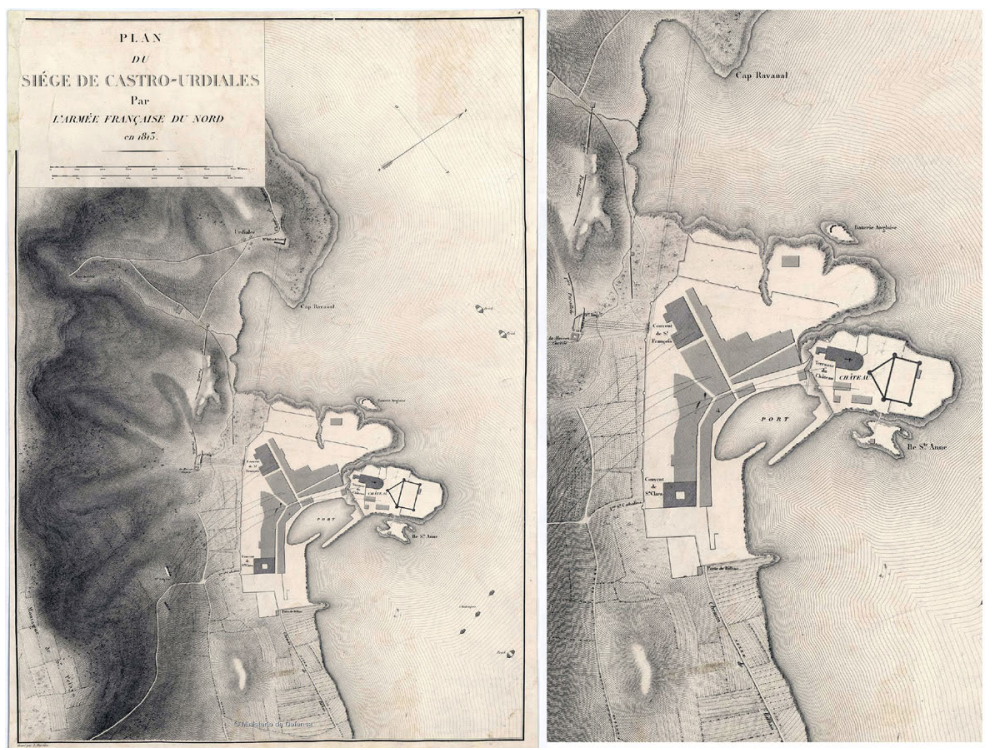

Fuente: Plan du siége de Castro-Urdiales par l’armée française du Nord en 1813 / gravé par A. Barriere. Archivo General Militar de Madrid. a) mapa completo y b) fragmento

Este plano es la primera representación cartográfica de la villa de que disponemos y se hace con un objetivo estratégico militar, lo que explica que en el mapa interese más el entorno que la ciudad en sí mis$\mathrm{ma}^{6}$. No obstante, el tejido urbano, manzanas edificadas y trama viaria, está representado con suficiente detalle, aunque de forma esquemática, a diferencia de lo que era habitual hasta ese momento, la representación del casco urbano como un conjunto macizo sin distinciones internas (Castañón y Puyo, 2008:72).

6 La existencia de este mapa se explica por el papel desempeñado por Castro Urdiales en el contexto de la Guerra de la Independencia, en relación con su posición estratégica entre los puertos cantábricos, como centro logístico para abastecimiento de tropas y para mantener la comunicación con Francia (Palacio, 2008). La villa, que estuvo largo tiempo ocupada por las tropas francesas, fue recuperada el 8 de julio de 1812 por la División de Iberia de Longa, su puerto utilizado como centro de recepción de los efectos enviados por los ingleses a la guerrilla desde La Coruña y como base de una flotilla inglesa. El interés en recuperar la plaza por parte del ejército francés en su retirada explica el asedio a que fue sometida desde marzo de 1813 hasta que, finalmente, fue tomada, saqueada y prácticamente destruida, el 11 de mayo del mismo año por las tropas napoleónicas franco-italianas mandadas por el general Foix, episodio conocido bajo el nombre de "la francesada". El plano aquí analizado corresponde, precisamente, al de dicho asedio, como se infiere no sólo del título que figura en la cartela superior sino también de la representación precisa de las posiciones de ataque y defensa en el entorno de la villa. 
En dicho plano se observan con meridiana claridad los tres sectores que conformaban el espacio urbano desde la Baja Edad Media: el castro, todavía rodeado por su propia muralla defensiva interior, y las dos medias villas, y todo el conjunto cercado por la muralla de origen medieval que, según documentos contemporáneos escritos, también franceses, tenía entre 5 y $7 \mathrm{~m}$ de altura y $2 \mathrm{~m}$ de espesor con sendas baterías en cada extremo.

Numerosas villas y ciudades portuarias dispusieron de planos levantados por los ingenieros militares encargados de las obras de sus respectivos puertos. Es también el caso de Castro Urdiales donde el primer director de su puerto, José $\mathrm{M}^{\mathrm{a}}$ Mathé, realizó en 1832 el levantamiento del plano de la costa y el puerto (Fig. 7) y el año siguiente dirigió la reconstrucción de las defensas de la villa ${ }^{7}$.

Figura 7. Mapa del puerto de Castro y ensenada de Urdiales en la primera mitad del siglo XIX

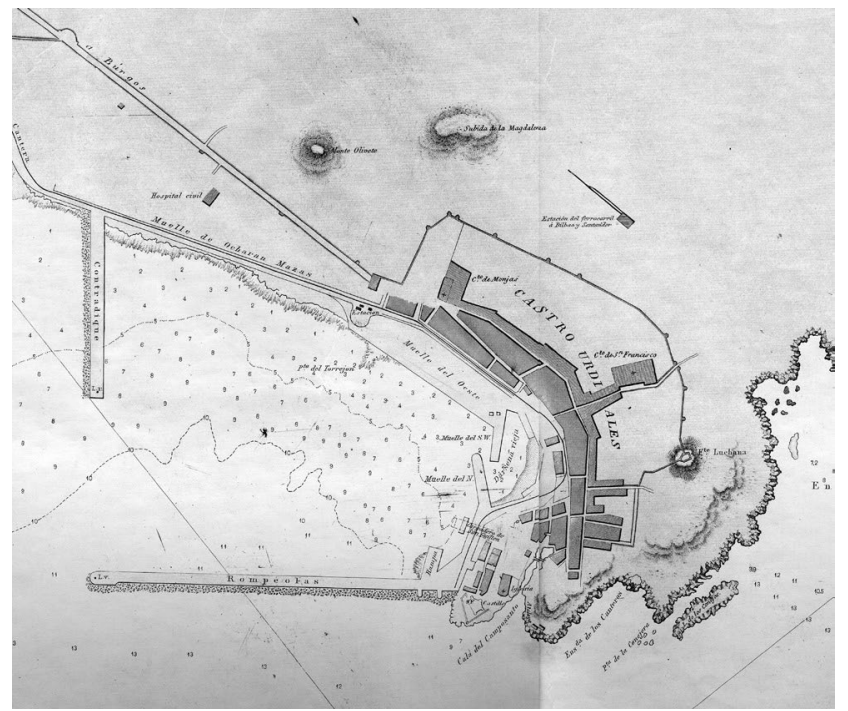

Fuente: Plano del Puerto de Castro y ensenada de Urdiales desde Punta de Mioño hasta el Rabanal. Levantado de Real Orden en 1832 por el Alférez de Navío de la Real Armada José María Mathé. Madrid, 1844. Costas de Europa en el Océano, Museo Naval (fragmento).

Por lo que se refiere a la forma y estructura de la villa, el plano de Mathé apenas añade nada al analizado antes. Sin embargo hay varios aspectos representados que requieren alguna explicación ya que se trata de elementos inexistentes en el momento del levantamiento del plano e, incluso, en la fecha en que, según la propia cartela, fue publicado, 1844. Es el caso del contradique y el rompeolas del puerto y del área de relleno sobre la que, en el mapa, aparece representado el "Muelle del Oeste"; son tres elementos que figuraban en el proyecto de reforma del puerto que presentó Mathé por las mismas fechas y que se llevaron a cabo muchos años después. Pero, además, figuran también otros que se realizaron mucho más tarde aún, a finales del siglo XIX, como es el caso del "Muelle de Ocharan Mazas", el cargadero de San Guillén y la estación del ferrocarril "a Bilbao y Santander", que sí tuvo una localización aproximada, pero lo fue del ferrocarril de Traslaviña a finales de la centuria.

Cabe suponer de todo ello que se trata de un mapa, probablemente elaborado en el último tercio del siglo sobre el original del de Mathé, en el que se representan, además, sus proyectos y otros posteriores, algunos de los cuales se llevaron a cabo y otros no; en cualquier caso, si no refleja fielmente la realidad de la villa en las fechas de su elaboración y publicación, sí expresa el proyecto de espacio urbano que ya se estaba pergeñando.

Los primeros planos de que se dispone para la mayor parte de las ciudades y villas españolas son los del Atlas de España y sus Posesiones de Ultramar de Francisco de Coello en cuyas hojas, y con la finalidad ornamental de rellenar los espacios vacíos, se insertaron los planos de la capital y de los principales núcleos urbanos de cada provincia a escala 1:10.000 y 1:20.000 (Quirós, 2009:25). Por tal motivo el Atlas es considerado por autorizados expertos en cartografía histórica como el repertorio de cartografía urbana más extenso ejecutado en España (Castañón et al., 2008: 127).

7 Más tarde el Ministerio de Marina le encargaría los planos topográficos de Santander y la península de Guarnizo. 
El plano elaborado por Coello en 1861 a escala 1:20.000 (Fig. 8) muestra la misma forma urbana que los anteriores; no obstante, al igual que en el atribuido a Mathé, en él quedan recogidos los dos proyectos del ingeniero del puerto que, hechos realidad varias décadas más tarde, iniciarán la transformación urbanística de la villa: el de un antepuerto o dársena nueva y, vinculado con él, el de una "población proyectada" erigida sobre los terrenos ganados al mar delante de la Calle de la Mar para la construcción de los nuevos muelles.

Figura 8. Plano de la villa de Castro Urdiales a mediados del siglo XIX
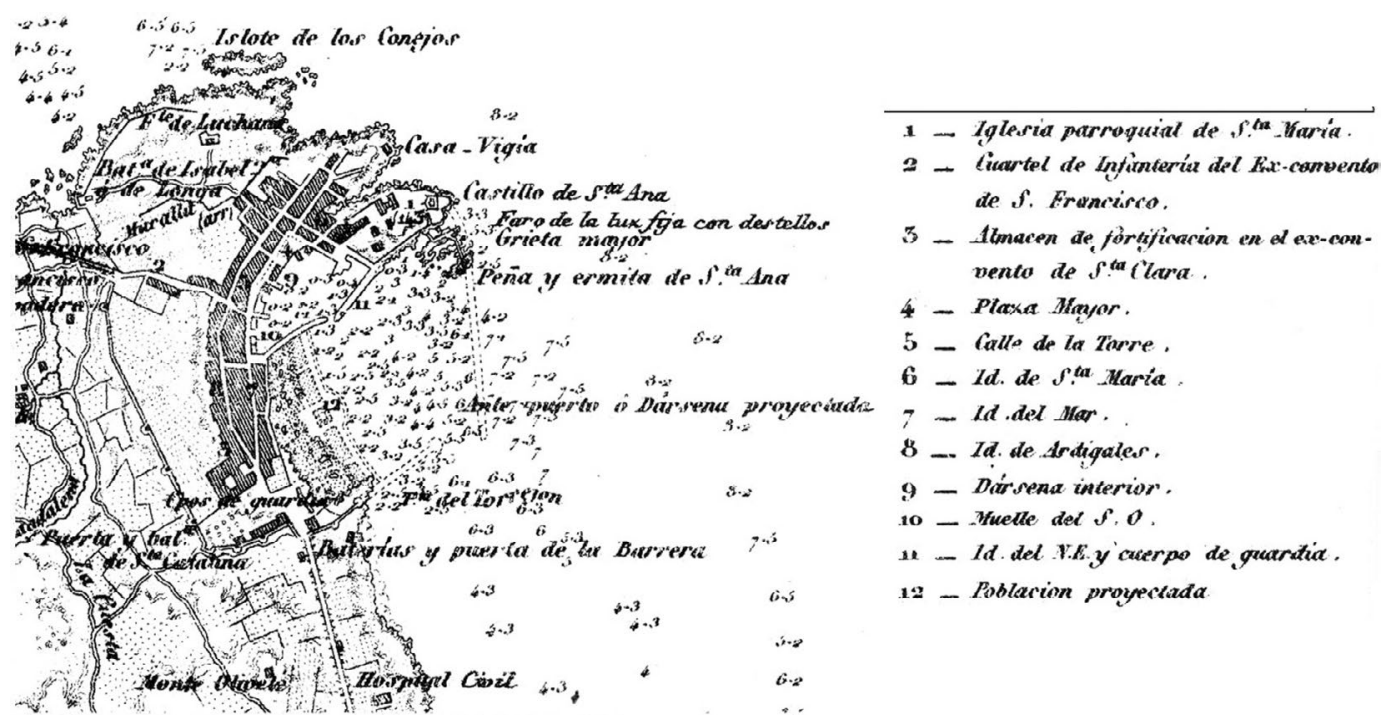

Fuente: Francisco Coello de Portugal y Quesada: Atlas de España y sus Posesiones de Ultramar, Hoja de la Provincia de Santander (1861), Biblioteca Nacional de España (fragmento).

Tal ampliación no había tenido lugar tampoco antes del último cuarto del siglo XIX como puede apreciarse en el mapa de 1874 (Fig. 9), en el que puede observarse como el espacio urbano edificado, ajustado estrictamente a la línea de base de la vieja dársena, coincide todavía con el casco medieval cercado.

Figura 9. El litoral de Castro Urdiales en 1874

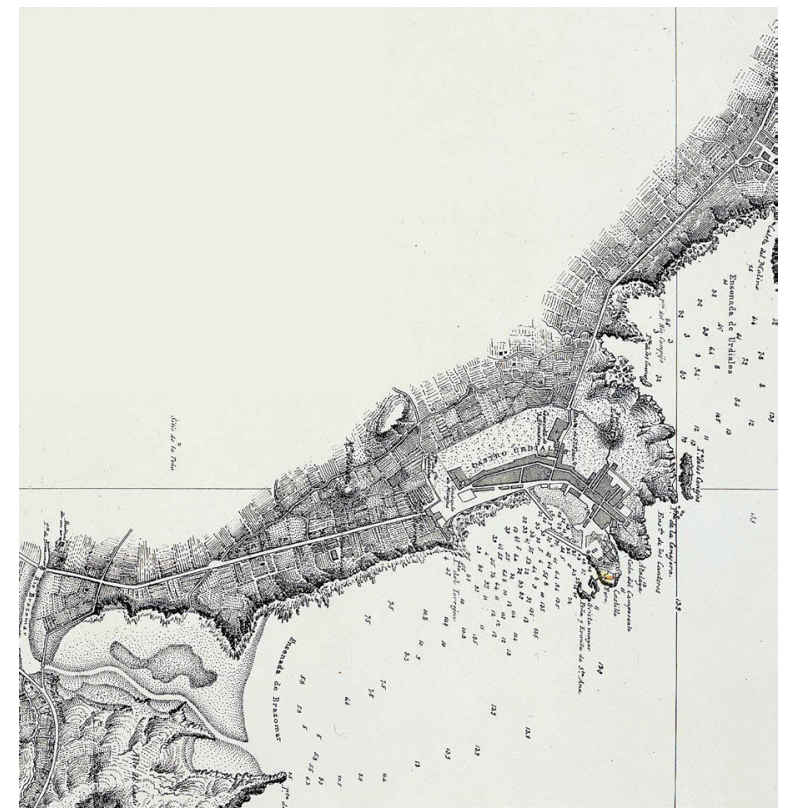

Fuente: Plano del puerto de Castro y ensenada de Urdiales, costa septentrional de España, José de Lorenzo y José María Riudavets y Monjo, Dirección de Hidrografía. Biblioteca Nacional de España (fragmento). 
Las primeras modificaciones estuvieron vinculadas, como se apuntó antes, a las obras de mejora y ampliación del puerto. La construcción de un dique y un muelle nuevo al sureste de la vieja dársena (1881) implicó el relleno del espacio situado delante de la Calle de la Mar, entre ésta y el nuevo muelle. Sobre estos terrenos ganados al mar, pero todavía dentro del antiguo espacio intramuros, se trazó una nueva calle y paseo (los actuales Calle de la Constitución y Parque de Amestoy) y una manzana de modernas casas plurifamiliares erigidas a partir de 1883 y, en particular, a comienzos del siglo XX, que configuraron la fachada portuaria burguesa de la moderna ciudad industrial ${ }^{8}$.

El nuevo espacio edificado finalizaba a la altura de la antigua puerta meridional de la muralla, la de La Barrera, de donde partía el camino de Bilbao. Una vez derribado el lienzo correspondiente se construyó, sobre el suelo liberado y parte de los terrenos del desamortizado convento de Santa Clara, un área ajardinada, el Paseo de la Barrera y Los Jardinillos, que articulaban el núcleo urbano tradicional con las nuevas calles y edificios que iban surgiendo en los terrenos situados detrás del muelle de Ocharan, la primera ampliación urbana que desbordaba el núcleo amurallado de origen medieval.

El origen de este nuevo sector urbano se encuentra en el proyecto para la mejora y reforma del puerto concedido a Luis Ocharan, quien había obtenido al mismo tiempo el espacio comprendido entre el Hospital de San Nicolás, en el Camino Real hacia Bilbao, y la zona conocida como La Pesquera. Sobre estos terrenos se inició la primera y fundamental ampliación extramuros del casco histórico, que adoptó la forma de una ciudad jardín, articulada en torno al Paseo de la Playa de Brazomar y el antiguo camino de Bilbao, el actual Paseo de Menéndez Pelayo, con viviendas unifamiliares, villas y palacetes de veraneo para la alta burguesía industrial.

Prolongándose de sureste a noroeste, el Paseo de la Playa de Brazomar (hoy Paseo de Luis Ocharan Mazas), los Jardinillos de La Barrera y la Calle y Parque de Eguilior (Calle de la Constitución y Parque de Amestoy en la actualidad), configuraron una nueva fachada marítima de carácter burgués, que sirvió de línea básica para el inminente crecimiento en superficie de la ciudad y la transformación definitiva de la morfología urbana conservada desde la Edad Media: el plano de forma semicircular, apoyado en la dársena, fue sustituido por el de un espacio urbano que se alargaba siguiendo la línea del viejo puerto y los nuevos muelles (Fig. 10).

Figura 10. La nueva fachada marítima de Castro Urdiales a principios del siglo XX

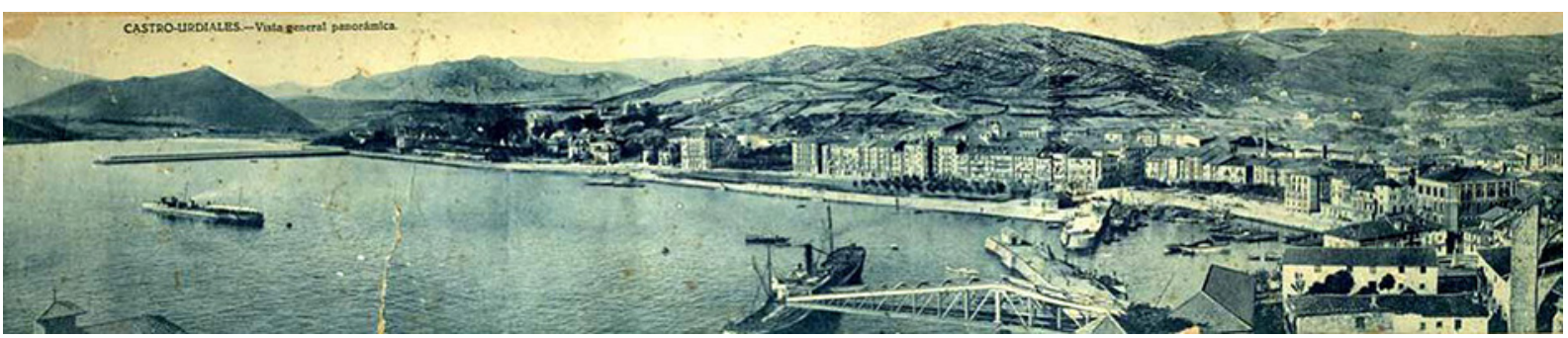

Fuente: Centro de Documentación de la Imagen de Santander.

Los cambios urbanísticos mencionados se realizaron sin una planificación previa a pesar de la existencia de un proyecto de reforma y ensanche reflejado en el plano del casco levantado por el arquitecto municipal, Eladio Laredo, en $1895^{9}$ (Fig. 11). Al contrastar este plano con alguno de los anteriores, se ve que el tejido urbano del casco histórico (resaltado en gris oscuro) permanece prácticamente intacto y no ha experimentado más ampliación que la colmatación de algunas manzanas en el espacio comprendido entre las calles Rúa Mayor, Ardigales y La Ronda, trazada esta última sobre la antigua muralla, algunos de cuyos paños aún quedaban en pie.

El modelo urbanístico propuesto (en color rosado) se basaba en la construcción de manzanas achaflanadas de grandes dimensiones, articuladas por un tejido viario casi ortogonal, pero adaptado a la forma semicircular del núcleo histórico preexistente. El conjunto se organizaba a partir de un eje transversal principal, la Calle de Santander, que unía el puerto con la antigua puerta de San Francisco, y varias calles

8 El 18 de diciembre de 1909 el Rey Alfonso XIII concedió a la, hasta entonces, Villa de Castro Urdiales, el título de ciudad, según un Real Decreto que fue remitido al Ayuntamiento por el presidente del Consejo de Ministros y ministro de la Gobernación, Segismundo Moret. 9 El plano original, sin memoria alguna, se conserva en el Archivo Municipal de Castro Urdiales. Plano del Casco Antiguo. 11 de diciembre de 1895, firmado por Eladio Laredo (Arquitecto Municipal). 
que siguen en paralelo la traza de las medievales, apoyada en la línea de la costa, de la muralla y el tramo urbano de la vía férrea.

Figura 11. Plano del Casco Antiguo de Castro Urdiales y proyecto de ensanche y reforma (Eladio Laredo, 1895)

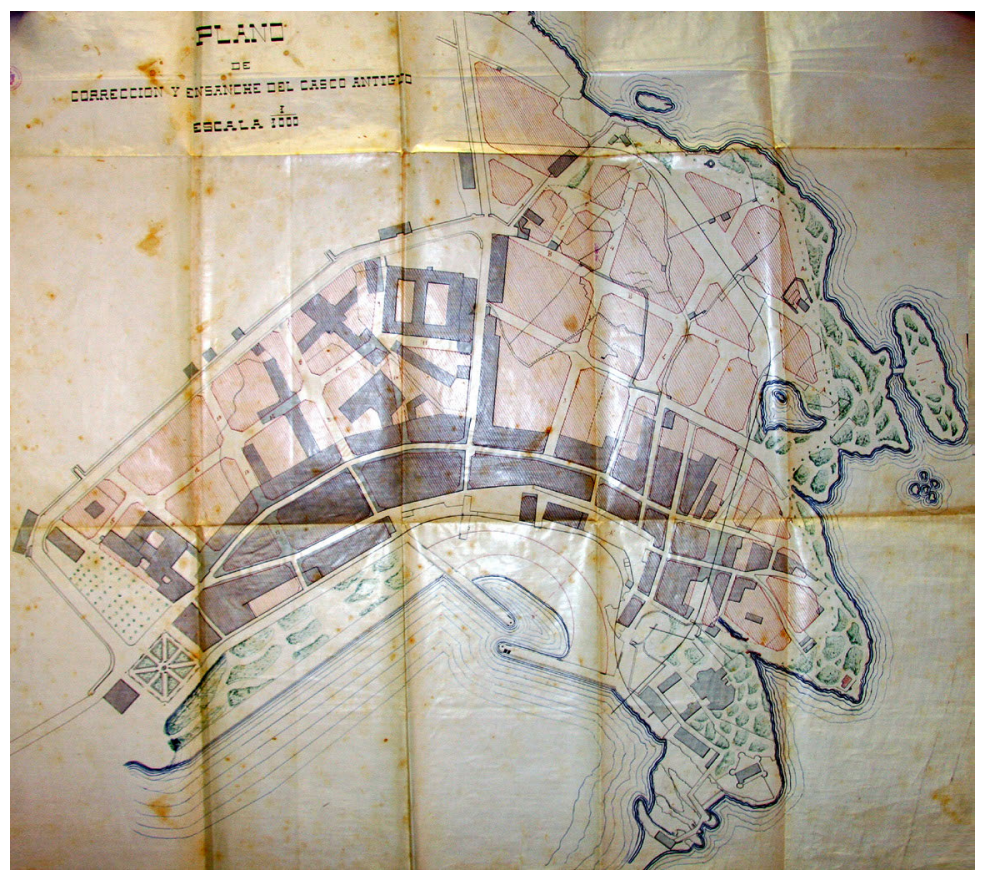

Fuente: Archivo Municipal de Castro Urdiales. Leg. 1681, doc. 6.

La construcción de las líneas de ferrocarril, casi coetánea al proyecto de ensanche y, probablemente, causa ocasional de su elaboración, tuvo un extraordinario impacto en la estructura y la morfología urbanas. En particular la del ferrocarril Castro-Alén cuyo proyecto definitivo consistía en una línea que bordeaba el casco histórico consolidado, siguiendo en paralelo la traza de la antigua muralla, con la que coincidía, incluso, en algunos tramos: entraba en el espacio urbano edificado por la bajada del Chorrillo, luego atravesaba sobre un viaducto la zona de Los Huertos hasta alcanzar, ya junto al mar, el Pedregal de Señá Santiaga, también conocido como "Pedregal de las mujeres", que fue rellenado parcialmente.

Esta línea de ferrocarril, además de constituir un nuevo dogal para la ampliación de la ciudad en contigüidad con el casco histórico, entraba literalmente en el corazón de éste ya que cortaba la histórica calle de San Juan y, tras rebasar el matadero viejo, accedía al cargadero a través de un túnel que perforaba la colina de Santa María, el antiguo castro.

Uno de los aspectos esenciales del proyecto de Eladio Laredo parece consistir, precisamente, en el relleno del suelo libre intramuros y en su ampliación en el área de Los Huertos y La Atalaya, donde la muralla ya había sido derribada completamente para permitir el trazado de la línea del ferrocarril Castro-Alén que, como se observa en el plano, atravesaba aquí el sector más antiguo del casco medieval.

La vía férrea de Castro Urdiales a Traslaviña llegaba a la villa a través de un túnel por el que se accedía al área de Brazomar y, desde allí, continuaba en paralelo a la vía del ferrocarril de Castro-Alén pero, a diferencia de éste, no penetraba en el casco consolidado sino que finalizaba en la estación construida en el borde del espacio urbano. Desde la estación se construyó un ramal de enlace, que bordeaba la ciudad, para llevar el mineral de hierro hasta la ensenada de Urdiales, en la que se efectuaba su embarque en sendos cargaderos de tipo cantilever.

El suntuoso edificio de la estación principal de la línea, erigido entre 1899 y 1902, ocupaba una amplia superficie situada a escasa distancia de la muralla medieval, de la que, para construirlo, hubo que derribar varios lienzos que aún permanecían en pie, de manera que las instalaciones de la propia estación y las vías de acceso se convirtieron también en un nuevo cinturón que ciñó el núcleo histórico y dificultó el crecimiento de la ciudad en el sector suroriental. La articulación entre la estación de ferrocarril, el centro urbano y el puerto se realizó mediante el trazado de un nuevo vial, la Bajada de la Estación que, después de atravesar la vía construida sobre la antigua muralla, la Calle de la Ronda, se dirigía hacia el espacio 
comprendido entre La Plazuela y el Muelle de Eguilior a través de las calles de Linares Rivas (Antonio Hurtado de Mendoza en la actualidad) y de Melitón Pérez Camino.

\subsection{La dinámica urbanística durante la primera mitad del siglo $X X$}

En 1907 Eladio Laredo elaboró otro Proyecto de Reforma y Ensanche de Castro Urdiales, probablemente similar al anterior, del que sí se conserva la memoria correspondiente, aunque sin plano en esta ocasión. El proyecto se centraba en la urbanización del área intramuros en torno al desamortizado convento de San Francisco ${ }^{10}$.

Casi veinte años después, en 1927, el mismo arquitecto volvió a presentar un nuevo proyecto de urbanización que queda justificado en la pertinente memoria por la existencia de "habitaciones insalubres de la gente marinera" y la necesidad de construir "vivienda barata e higiénica...". En el plan se pone de manifiesto el objetivo de adecuar la estructura urbana a la configuración de su base socioeconómica. En este sentido, Eladio Laredo proponía estructurar la ciudad a partir de tres zonas de acuerdo con los usos y el contenido social: "agrupar la población de lujo y de recreo alrededor de la playa de los baños, dejando el casco antiguo de la población para sus diversas industrias, siempre molestas para una vida higiénica y por último dedicar a la vivienda del proletariado la población que nosotros proyectamos"11.

En realidad se trataba de un plan para ampliar la superficie edificada en el espacio comprendido entre las vías del ferrocarril Castro-Alén, la antigua muralla y los terrenos del ex convento de San Francisco, donde se planteaba el trazado de varias calles para la construcción de barrios obreros; este plan estaba vinculado a los anteriores y al Proyecto de Urbanización de la zona de Los Huertos (1926-1929) ${ }^{12}$.

Las transformaciones reseñadas hasta aquí quedan fielmente expuestas en el plano de población a escala 1:5.000 elaborado en 1927 como parte de los trabajos realizados para el levantamiento del mapa topográfico (Fig. 12), el más detallado de los disponibles hasta ese momento, que representa con gran nitidez el crecimiento reciente del espacio urbano en varias direcciones. En el sector central del casco, la edificación se ha extendido entre la calle medieval de Ardigales y la de La Ronda (Paseo de Pereda en el plano) y las transversales de Linares Rivas, de unión de la estación ferroviaria con el puerto, y la calle de Santander, la antigua vía que conducía a la puerta de San Francisco.

Figura 12. Plano de población de Castro Urdiales en 1927

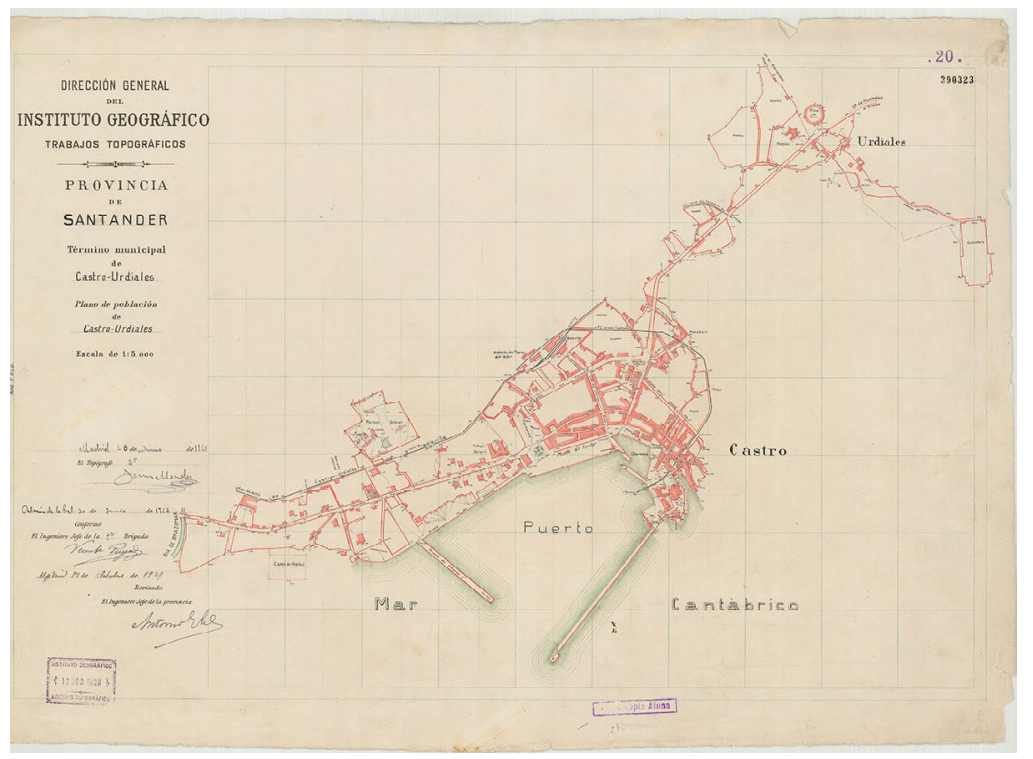

Fuente: Planos y minutas para el primer levantamiento del mapa topográfico nacional, Plano de población 1:5.000. Instituto Geográfico Nacional. Edición de la Cartoteca del Departamento de Geografía de la Universidad de Cantabria.

10 "Proyecto de reforma y ensanche de Castro Urdiales" firmado por Eladio Laredo en Madrid a 9 de noviembre de 1907. Archivo Municipal de Castro Urdiales, Leg. 1688, Exp. 9.

11 Proyecto de urbanización de 1927, Archivo Municipal de Castro Urdiales, Leg. 606, Exp. 1

12 Expediente de urbanización y ensanche de la zona de Los Huertos, año 1926. Archivo Municipal de Castro Urdiales, Leg. $2095-1$. 
En el polígono definido por estas cuatro calles se ha trazado ya una nueva vía transversal, la de Javier Echavarría, que acaba en la plaza de San Francisco, dispuesta sobre el solar del convento del que aún persistían los restos de la iglesia. Al sur de La Ronda/Paseo de Pereda, parece haberse iniciado ya la colmatación de los terrenos comprendidos entre esta calle y las vías férreas, en particular en torno a la estación de Traslaviña, articulados por la Calle de la Estación.

La ampliación es aún más notable en el sector noroccidental, en continuidad con la media villa de arri$b a$, entre la vieja calle de la Rúa y la recién trazada calle del Siglo XX, y en el sector de La Atalaya, donde figura ya el barrio previsto en el Plan de Urbanización de 1926-1929, probablemente en construcción en el momento del levantamiento del plano, atravesado por las vías del ferrocarril de Castro-Alén que llegaba hasta el cargadero de San Guillén. Hacia el sur de este barrio empezaba a configurarse ya el área urbana de Los Huertos articulada por la calle del mismo nombre, que enlazaba el nuevo matadero con la plaza de San Francisco y el mercado.

Hacia el sureste el área urbana edificada también había comenzado a extenderse entre la calle de Linares Rivas y el paseo de La Barrera a uno y otro lado del Paseo de Pereda/La Ronda. El Paseo de La Barrera, limitado por el edificio del Teatro de la Villa y los Jardinillos, funcionaba como nuevo espacio urbano de ocio y sociabilidad más allá del cual el sector construido extramuros presenta un tejido urbano con una textura muy diferente del resto. Era la nueva "ciudad jardín", formada por palacetes y villas de recreo rodeadas de jardines y separadas por amplios espacios sin edificar, que se iba extendiendo a lo largo del antiguo Camino Real hacia Bilbao, ahora Paseo de Menéndez Pelayo, entre el muelle de Ocharan, la playa de Brazomar y las vías del ferrocarril. Al otro lado de éstas se situaba el extenso conjunto arquitectónico "Toki-Eder", el dominio del Parque de Ocharan donde el empresario vasco-castreño había erigido, como residencia particular, varias edificaciones construidas por el arquitecto Eladio Laredo.

En el mismo plano están representados e identificados los edificios más emblemáticos de cualquier ciudad española que se preciase de su categoría y modernidad. En el NO la plaza de toros, en la aldea/ barrio de Urdiales, junto al antiguo Camino Real, ahora carretera de Bilbao a Santander; muy cerca el moderno hospital civil, también junto a la carretera y rodeados todavía ambos edificios de huertos y otros espacios de uso agrario; el cementerio modernista de La Ballena sobre el promontorio de la punta de El Rabanal que cierra la ensenada de Urdiales por el Oeste; frente a aquél, en el otro extremo de la ensenada de Urdiales, el flamante matadero. En el sector central del núcleo urbano, el mercado de la plaza de San Francisco, la estación del ferrocarril de Traslaviña y el depósito de máquinas del de Alén, el Teatro de la Villa en el Paseo de La Barrera, el Colegio Barquín al comienzo del Paseo de Menéndez Pelayo, el campo de foot-baal (sic) en las proximidades de la playa de Brazomar, etc.

Figura 13. Plano de Castro Urdiales en 1936

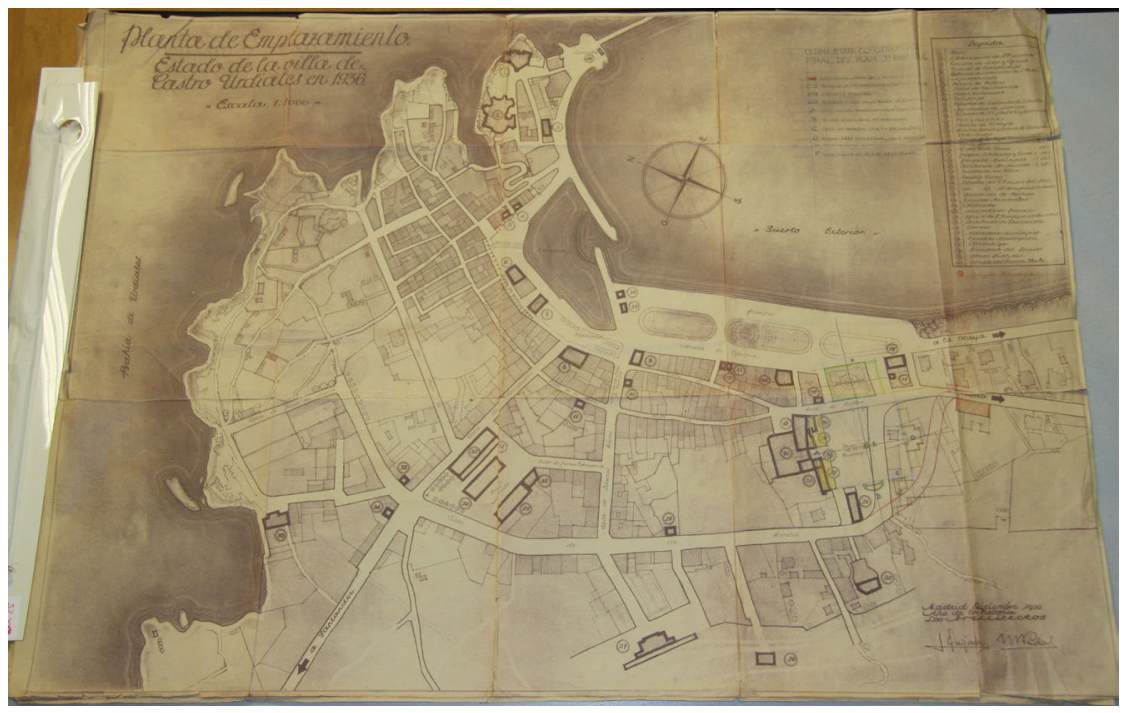

Fuente: Archivo Municipal de Castro Urdiales. Leg. 1141, Exp. 2.

La nueva coyuntura de estancamiento económico y poblacional que experimentó la ciudad desde la segunda década del siglo XX tuvo un efecto paralizador sobre el proceso de construcción residencial al 
tiempo que también quedaron detenidos los de reforma y ampliación del espacio urbano ${ }^{13}$. Así lo atestigua el plano de la ciudad levantado en 1936 (Fig. 13), aunque firmado por los arquitectos Luis Quijada Martínez y José Menéndez-Pidal Álvarez en diciembre de 1939, "año de la victoria", que fueron quienes, sobre el mapa original, trazaron las líneas básicas del proyecto de reforma parcial realizado a partir de ese mismo año $0^{14}$.

El proyecto post-bélico fue elaborado con el propósito de organizar el área urbana comprendida entre el Paseo de La Barrera y la Calle de Santander, aprovechando para ello los terrenos aún sin edificar del ex convento de Santa Clara. De acuerdo con la ideología urbanística imperante en el momento, todo el sector suroccidental del casco histórico debería quedar organizado a partir de un sistema de relaciones articulado por el Parque de Eguilior, el mercado de San Francisco y un nuevo espacio central de carácter religioso y cívico. La realidad del proyecto consistió básicamente en la construcción en 1941 de un Centro Cívico donde deberían instalarse los organismos administrativos oficiales, la sede de la Falange y un nuevo Ayuntamiento, además de viviendas para maestros y empleados municipales. Estos edificios estaban distribuidos alrededor de la plaza de La Barrera, que debía adquirir la función de nuevo centro urbano de servicios, a modo de las plazas mayores tradicionales, y elemento articulador del casco histórico y la ciudad jardín burguesa. Asimismo, el plan preveía la construcción de la iglesia del Sagrado Corazón, la apertura de nuevas calles y la prolongación de otras (las de Iglesia Nueva, Timoteo Ibarra, Juan de la Cosa y Javier Echevarría).

La ciudad apenas cambió en los años siguientes, ni en su tamaño ni en su forma (Fig. 14), ya que fueron muy pocas las actuaciones urbanísticas reseñables durante los años cuarenta y cincuenta. Se produjo, por una parte, la consolidación del área de la ciudad jardín de Brazomar, donde siguieron construyéndose numerosas villas de veraneo e, incluso, algunas pequeñas urbanizaciones sobre terrenos municipales cedidos en 1944 para la edificación de casas-chalets protegidas. Como la de cuatro chalets de Eduardo Sanz Martín y otra de cuatro chalets bifamiliares en la calle María Aburto; ambas situadas entre el Paseo de la Playa y el Paseo de Luis Ocharan Mazas.

Figura 14. Vista aérea de Castro Urdiales a mediados de los años 40

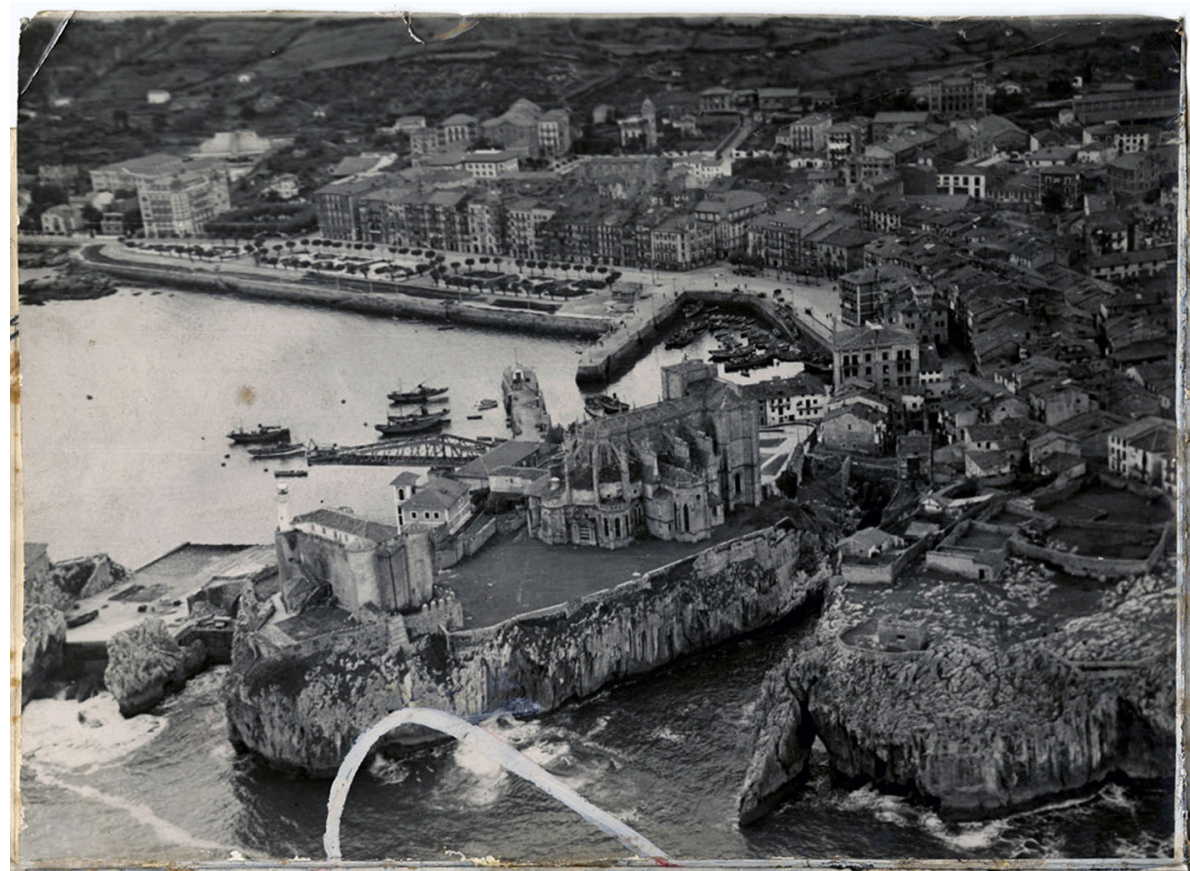

Fuente: Centro de Documentación de la Imagen de Santander.

13 “¿Quién duda que la época más floreciente de Castro Urdiales ha sido en la época de la construcción de los dos ferrocarriles y principios del puerto? En aquellos momentos parecía que Castro olvidándose de sí mismo, exageraba tanto la nota de su bien estar como hoy día deplora su pobreza y mal estar" "Proyecto de reforma y ensanche de Castro Urdiales" firmado por Eladio Laredo en Madrid a 9 de noviembre de 1907. Archivo Municipal de Castro Urdiales, Leg. 1688, Exp. 9.

14 Proyecto de Reforma Interna de la villa de Castro Urdiales, año 1939. Archivo Municipal de Castro Urdiales, Leg. 1141, Exp. 2. 
Por otra parte, finalizó la colmatación de los solares vacíos del casco histórico, hasta alcanzar el límite marcado por la derruida muralla medieval, en particular en el área suroriental. Es aquí donde se construyeron algunos bloques de viviendas bonificadas para la clase media, en el entorno de la nueva iglesia del Sagrado Corazón, las calles de La Ronda y Javier Echevarría, Plaza del Mercado, etc.

Un carácter bien distinto tenían los bloques de vivienda obrera construidos en los años cincuenta por la Obra Sindical del Hogar en la zona de Los Huertos, en solares que quedaban sin edificar del antiguo convento de San Francisco (Grupo Maestro Morondo de 112 viviendas entre las calles Silvestre Ochoa, Aranzal y Santander), un bloque de 50 viviendas de la Obra Social de la Falange en la prolongación de Juan de Mena, las viviendas protegidas de las calles Bilbao, República Argentina, Timoteo Ibarra, etc. El mismo sentido tenía la Barriada de los Pescadores de 90 viviendas edificadas por el Instituto Social de la Marina en cuatro bloques en la zona de El Pedregal y Los Huertos. Saturada este área urbana, claramente definida por su función residencial para la clase obrera, a finales de los años cincuenta y principios de los sesenta comenzaron a utilizarse algunos núcleos próximos a la ciudad para edificar viviendas para obreros (Santullán) y mineros (Mioño).

Un mapa fechado en 1960 (Fig. 15) pone de manifiesto la atonía urbanística de Castro Urdiales a lo largo de las tres décadas anteriores a esa fecha, si bien no refleja fielmente los pequeños cambios que se había producido ya que, básicamente, el mapa es una reproducción del de 1928 con leves retoques formales, como se explicita en la cartela. No obstante, el inicio de la transformación urbanística de Castro Urdiales, originada por su consolidación como núcleo turístico de veraneo para capas de población cada vez más amplias, no se produjo hasta los años sesenta y setenta del siglo XX. Es entonces cuando las actividades terciarias, tanto las vinculadas al turismo como a la prestación de servicios a la población local y comarcal, se convirtieron en la base económica de una ciudad que modificó de nuevo su funcionalidad y, a partir de esta mudanza, la estructura y morfología del espacio urbano (Delgado, 2011b).

Figura 15. Castro Urdiales a mediados del siglo XX

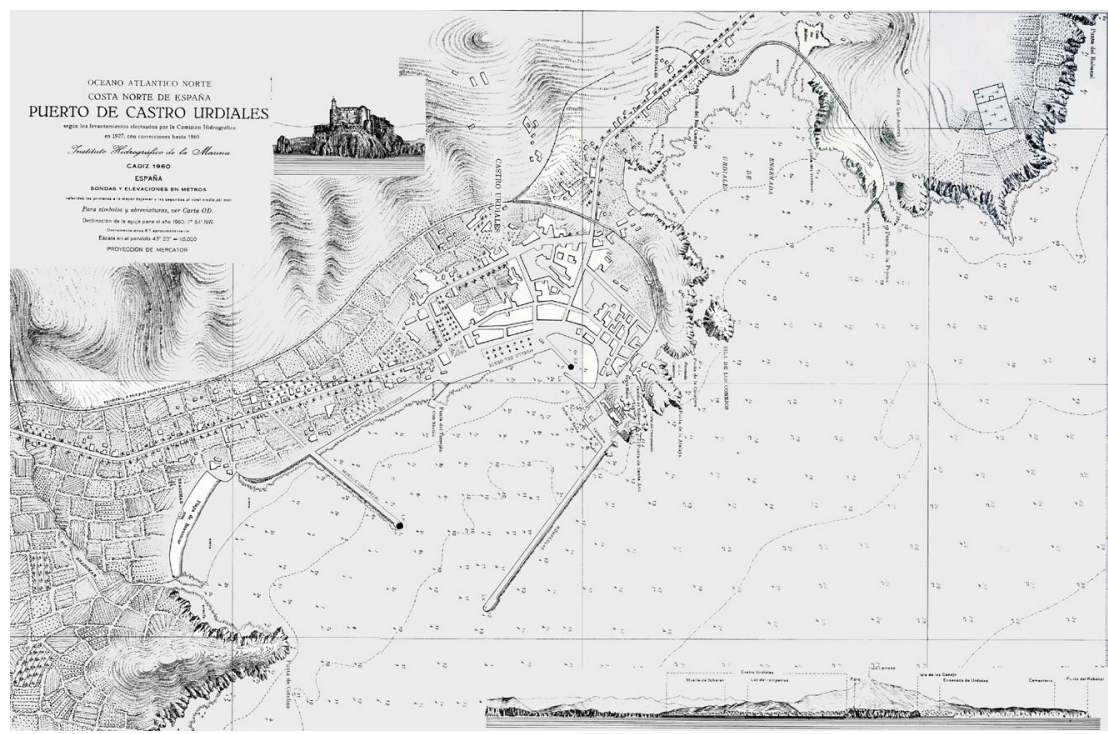

Fuente: Plano del Puerto de Castro Urdiales según los levantamientos efectuados por la Comisión Hidrográfica con correcciones hasta 1960. Servicio Hidrográfico de la Armada, 1928. Archivo General Militar de Madrid

\section{BIBLIOGRAFÍA}

ALVARGONZÁLEZ, R. (2002): "Notas sobre cartografía urbana histórica de España", Historia Contemporánea, $\mathrm{n}^{\circ} 24$, pp. 59-81.

CANOSA, E. y GARCÍA, A. (2008): "Cartografía del territorio español en el siglo XVIII", Madrid 1808. Guerra y Territorio. Mapas y planos (1808-1814). Madrid, Ayuntamiento de Madrid, pp. 37-66.

CASTAÑÓN, J.C. y PUYO, J-Y. (2008): "La cartografía realizada por el ejército napoleónico durante la Guerra de la Independencia", Madrid 1808. Guerra y Territorio. Mapas y planos (1808-1814). Madrid, Ayuntamiento de Madrid. 
CASTAÑÓN, J.C. et al. (2008): "La herencia cartográfica y el avance del conocimiento geográfico de España", Madrid 1808. Guerra y Territorio. Mapas y planos (1808-1814). Madrid, Ayuntamiento de Madrid.

DELGADO, C. (2011a): "Infraestructuras de transporte y urbanización: el caso de Castro Urdiales (Cantabria)", Revista de Historia [tst], Transportes, Servicios y Telecomunicaciones, junio 2011, núm. 20, $106-137$

DELGADO, C. (2011b): "Castro Urdiales (Cantabria), de «villa marinera» a ciudad de servicios. La transformación urbanística de una «ciudad de frontera»", Ería, n 86, pp. 237-270.

LÍTER, C., et al. (1994): Cartografía de España en la Biblioteca Nacional. Siglos XVI al XIX. Catálogo de Fondos, Madrid, Ministerio de Cultura.

MADOZ, P. (1845-1850): Diccionario geográfico-histórico-estadístico de España y sus posesiones de Ultramar. Madrid, 16 vols.

MARTÍN, L. y RIVERA, B. (1990): Catálogo de Cartografía Histórica de España del Museo Naval, Madrid, Museo Naval, $435 \mathrm{pp}$.

MIÑANO, S. (1826-1829): Diccionario geográfico-estadístico de España y Portugal, Madrid, 11 vols.

OJEDA, Ramón (2010): Miradas a un pasado no muy lejano: Castro Urdiales.

PALACIO, R.(2008): "Importancia estratégica de Cantabria durante la guerra de la independencia: vías de comunicación y plazas fuertes". Monte Buciero, n 13, págs. 221-254.

QUIRÓS, F. (2009): Las ciudades españolas en el siglo XIX, Gijón, Ed. Trea, 430 pp.+ CD. Reedición actualizada de su obra Las ciudades españolas a mediados del siglo XIX, Valladolid, Ámbito, 1991.

QUIRÓS, F. (2008): "La Guerra de la Independencia y la renovación del conocimiento cartográfico peninsular", Madrid 1808. Guerra y Territorio. Mapas y planos (1808-1814). Madrid, Ayuntamiento de Madrid, 27-35.

QUIRÓS, F. (2008) y GARCÍA, J. (2005): "Pascual Madoz y la lectura del territorio: el Diccionario Geográfico y el Atlas de España y sus posesiones de Ultramar", Pascual Madoz (1805-1870): un político transformador del territorio: Homenaje en el bicentenario de su nacimiento, I. Pascual Madoz, Madrid, pp. 53-70.

VILLÈLE, M-A. de (2008): "Acerca del trabajo cartográfico de los oficiales franceses en España, 18081814”, Madrid 1808. Guerra y Territorio. Mapas y planos (1808-1814). Madrid, Ayuntamiento de Madrid, pp. 23-26. 